\title{
Tissue-resident natural killer cells in the livers
}

\author{
Hui Peng ${ }^{1^{*}} \&$ Zhigang Tian ${ }^{1,2}$ \\ ${ }^{1}$ Institute of Immunology and The CAS Key Laboratory of Innate Immunity and Chronic Disease, School of Life Sciences and Medical Center, \\ University of Science and Technology of China, Hefei 230027, China; \\ ${ }^{2}$ Collaborative Innovation Center for Diagnosis and Treatment of Infectious Diseases, State Key Laboratory for Diagnosis and Treatment of \\ Infectious Diseases, First Affiliated Hospital, College of Medicine, Zhejiang University, Hangzhou 310003, China
}

Received October 31,2016; accepted November 15, 2016; published online November 30, 2016

\begin{abstract}
Nature killer (NK) cells are important lymphocytes of the innate immune system, well known for their pivotal roles in immune surveillance and defense against tumor and virus-infected cells. Current studies have revealed that NK cells are not a homogeneous population, but instead consist of distinct subsets with diverse characteristics. As an organ with predominant innate immunity, the liver is enriched with NK cells, among which two distinct NK cell subsets have recently been identified: conventional NK (cNK) cells and tissue-resident NK (trNK) cells. Liver trNK cells are markedly different from cNK cells in many aspects, representing a new lineage of innate lymphoid cell (ILC) family. Here, we summarize the phenotypic and functional features of liver trNK cells, and review current knowledge regarding developmental pathway of liver trNK cells. We also overview recent advances in human liver trNK cells and discuss the striking shared hallmarks of trNK cells in different tissues.
\end{abstract}

liver, conventional NK cell, tissue-resident NK cell, development, function

Citation: $\quad$ Peng, H., and Tian, Z. (2016). Tissue-resident natural killer cells in the livers. Sci China Life Sci 59, 1218-1223. doi: 10.1007/s11427-016-0334-2

\section{INTRODUCTION}

Natural killer (NK) cells are the prototype member of innate lymphoid cell (ILC) family (Spits and Di Santo, 2011). Since their discovery in the 1970s, many studies have shown the importance of NK cells in host defense against microbial infections and tumors (Dahlberg et al., 2015; Eissens et al., 2014; Sun et al., 2015). In particular, most of previous studies on NK cells have focused on mouse splenic and human peripheral blood NK cells, which are circulating and referred to as conventional NK (cNK) cells (Sojka et al., 2014b). However, NK cells have recently been attracting attention for their heterogeneous subsets based on tissue distribution (Rajagopalan, 2014; Shi et al., 2011).

The liver is a unique organ with predominant innate immu-

\footnotetext{
*Corresponding author (email: huipeng@mail.ustc.edu.cn)
}

nity, containing a large number of innate immune cells, such as Kupffer cells, NK cells, NKT cells and $\gamma \delta$ T cells (Gao et al., 2008; Ma et al., 2015). Earlier studies have indicated that hepatic NK cells were phenotypically different from splenic NK cells, and these findings were initially attributed to the abundant presence of cNK-cell developmental intermediates (Kim et al., 2002; Takeda et al., 2005). Until recently, we and others have showed that mouse liver NK cells can be divided into two distinct subsets based on CD49a and DX5 expression: One subset characterized as $\mathrm{CD} 49 \mathrm{a}^{-} \mathrm{DX} 5^{+}$is $\mathrm{cNK}$ cells as it resembles splenic NK cells and circulates in the blood (Peng et al., 2013; Sojka et al., 2014a). Another subset is tissue-resident NK (trNK) cells and characterized by the specific $\mathrm{CD} 4 \mathrm{a}^{+} \mathrm{DX5}^{-}$phenotype, residing in the liver sinusoid blood and conferring memory-like responses in contact hypersensitivity (CHS) models (Peng et al., 2013). Subsequent studies further revealed that liver trNK cells and cNK cells require 
different transcription factors for their development, thus representing separate developmental lineages (Constantinides et al., 2014; Daussy et al., 2014; Klose et al., 2014; Mackay et al., 2016).

\section{LOCATION AND ORIGINS OF LIVER TRNK CELLS}

The liver has two afferent vascular supplies, the portal vein and hepatic artery, the blood of which mixes together in the hepatic sinusoids (Jenne and Kubes, 2013; Racanelli and Rehermann, 2006). CD49a $\mathrm{DX}^{-} \mathrm{NK}$ cells reside neither in afferent nor in efferent blood of the liver; instead, they are present in the sinusoids (Peng et al., 2013). In line with these observations, analysis of parabiotic mice, which allow sharing of the blood circulation through joint circulation, revealed that liver $\mathrm{CD} 49 \mathrm{a}^{+} \mathrm{DX} 5^{-} \mathrm{NK}$ cells were mostly host derived, confirming their tissue-resident feature (Peng et al., 2013; Sojka et al., 2014b); however, liver CD49a ${ }^{-}$DX5 $5^{+}$NK cells are derived from both host and the other parabiont. Notably, liver trNK cells from mice in parabiosis for more than three months still remained host-derived, suggesting that liver trNK cells are not continuously replaced by bone marrow (BM)-derived precursors (Gasteiger et al., 2015). Consistently, in lethally irradiated mice that were transplanted with BM cells, liver trNK cells were significantly reduced as compared with those in normal mice (Peng et al., 2013). These findings raised the question of whether liver trNK cells are locally renewed (Yokoyama et al., 2013).

Liver is a major hematopoietic site during fetal life and maintains a few hematopoietic stem cells in adults (Crosbie et al., 1999; Kotton et al., 2005; Orkin and Zon, 2008; Taniguchi et al., 1996; Wang et al., 2012). Our previous study has indicated that hematopoietic progenitors in adult liver can generate liver trNK cells, which is likely one source for the replenishment of liver trNK cells (Peng et al., 2013). It is also plausible that liver trNK cells arising from the fetal period may locally self-renew and persist for life time, akin to tissue-resident macrophages (Figure 1).

\section{DEVELOPMENT OF LIVER TRNK CELLS}

Regarding cell development, liver trNK cells share common features with cNK cells but can be distinguished (Peng and Tian, 2015). Similar to T cells and B cells, trNK and cNK cells develop from common lymphoid progenitors (CLPs). Committed ILC progenitors, which have the potential to give rise to all ILC lineages but not other hematopoietic lineages, are downstream of CLPs. A progenitor subset characterized as $\mathrm{CXCR}^{+} \mathrm{Flt}^{-} \alpha 4 \beta 7^{+}$CLPs (known as CXCR6 ${ }^{+} \alpha \mathrm{LPs}$ ) has been reported to give rise to $\mathrm{cNK}$ cells, trNK cells and other ILC lineages, but not T and B cells (Yu et al., 2014). However, $\mathrm{CXCR}^{+} \alpha \mathrm{LPs}$ are very rare, and only $2.5 \%$ of them can

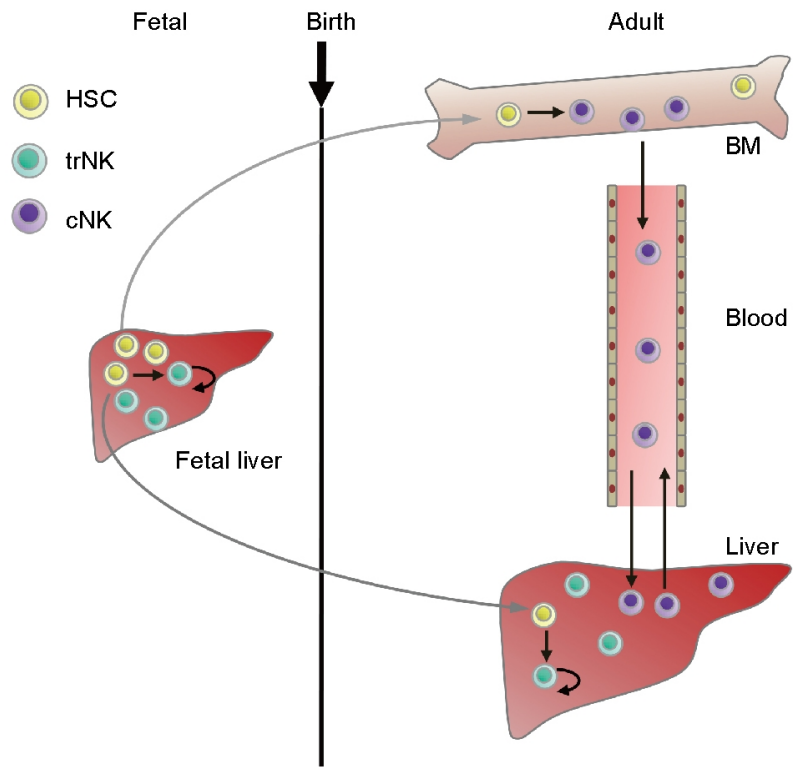

Figure 1 Possible origins of trNK cells in the adult liver under homeostasis. Liver trNK cells emerge during fetal life and persist with age. It is possible that the self-renewal of fetal liver trNK cells may contribute to the adult liver trNK-cell pool. Since the fetal liver also functions as an important haematopoetic organ, an alternative possible origin of trNK cells isthe intraheaptic progenitors, such as hematopoietic stem cells (HSCs), which are maintained in the adult liver and can persistently give rise to trNK cells. In contrast to the enigmatic origin of trNK cells, the generation of $\mathrm{cNK}$ cells and their development majorly take place in the bone marrow (BM).

generate all four ILC lineages at the clonal level (Yu et al., 2014). More recently, Lin $^{-} \mathrm{TCF}-1^{+} \mathrm{Thy}-1^{-} \mathrm{IL}-7 \mathrm{R} \alpha^{\text {lo-neg }}$ cells have been found to give rise to all ILC lineages (Figure 2), and thus termed as early ILC progenitors (EILPs) (Yang et al., 2015).

A branching point between cNK cells and other ILC subsets has been demonstrated. Lin ${ }^{-} \mathrm{Id} 2^{+} \mathrm{IL}-7 \mathrm{R} \alpha^{+} \mathrm{CD} 25^{-} \alpha 4 \beta 7^{+}$ cells, known as CHILPs, have the potential to give rise to all helper-like ILC lineages, including liver trNK cells, but could not give rise to cNK cells or T and B cells (Klose et al., 2014). Moreover, a subset of progenitors marked by PLZF expression represents a more restricted-development potential compared to CHILPs, since it could develop into liver trNK cells, ILC2s, ILC3s, but not cNK and LTi cells (Constantinides et al., 2014). These findings suggest liver trNK cells and cNK cells represent separate developmental lineages.

Remarkable progress has recently been made in the recognition of transcription factors that control the development of NK cell subsets at early stages (Zook and Kee, 2016). For example, TCF1 and NFIL3 are responsible for the generation of ILC progenitors, therefore affecting the development of trNK cells, cNK cells as well as other mature ILC subsets (Geiger et al., 2014; Seillet et al., 2014b; Yang et al., 2015; Yu et al., 2014). Notably, in NFIL3-deficient mice, CD49a ${ }^{+}$DX $5^{-}$trNK cells are reduced but still predominant in the liver, suggesting the existence of NFIL3-independent trNK cells (Crotta et al., 2014; Seillet et al., 2014a; Sojka et al., 2014a; Tang et al., 


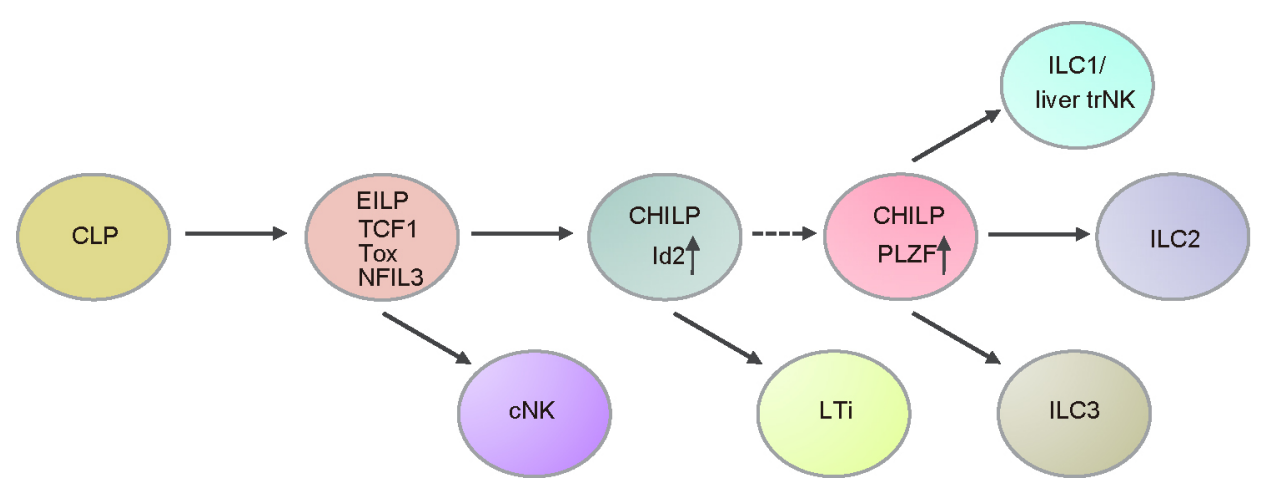

Figure 2 Development pathway of of innate lymphoid cells (ILCs). ILCs and adaptive lymphocytes develop from CLPs, which further differentiate into EILPs. EILPs are marked by the expression of TCF1 and can give rise to all known ILC lineages. Downstream of EILPs, Id2-expressing common helper-like ILC progenitors (CHILPs) lose the potential to develop into the cNK cell lineage, but can give rise to all helper-like ILC subsets. Upregulation of PLZF in CHILPs coincides with the loss of LTi cell differentiation potential but maintaining other ILC potential.

2016). Transcription factor T-bet is strictly required for the early development of liver trNK cells, but only has moderate effects in cNK cell development (Daussy et al., 2014; Tang et al., 2016). Moreover, PLZF and Hobit are also respectively required for the development of liver trNK but not cNK cells (Constantinides et al., 2014; Mackay et al., 2016). Additionally, as compared to cNK cells, liver trNK cells expressed low levels of Eomes, which is important for cNK cell development but does not impact liver trNK cells (Daussy et al., 2014; Gordon et al., 2012). Thus, liver trNK cells and cNK cells have differential transcription factor requirements.

\section{FUNCTIONS OF LIVER TRNK CELLS}

\section{Memory-like responses mediated by liver trNK cells}

Accumulating evidence has recently shown that NK cells possess certain features of immunological memory (O'Sullivan et al., 2015). NK cells can mount recall responses following specific activation by chemical haptens (O'Leary et al., 2006; Paust et al., 2010) or viruses (Foley et al., 2012; Gillard et al., 2011; Paust et al., 2010; Sun et al., 2009), or non-specific activation by cytokines (Cooper et al., 2009; Keppel et al., 2013), respectively. The first evidence for NK cell memory came from observations that mice devoid of $\mathrm{T}$ cells and B cells but possessing NK cells mediated CHS responses in a hapten-specific manner (O'Leary et al., 2006). Of particular interest, memory-like NK cells in CHS models were unexpectedly restricted to the liver, whereas splenic NK cells failed to mount CHS responses (O'Leary et al., 2006; Paust et al., 2010). Our later studies confirmed this phenomenon and further showed that transfer of liver trNK cells could confer the recall response in CHS models, but liver cNK cells was ineffective (Peng et al., 2013). However, it remains puzzling how liver trNK cells exert effector functions at the site of challenge. Another important issue to be addressed is how NK cells recognize different antigens since they do not express RAG-dependent antigen receptors.

\section{Potential roles of trNK cells in liver diseases}

The liver is an immune tolerant organ with unique predisposition for chronic infections by certain clinically important pathogens (Fahey et al., 2014; Xu et al., 2014; Yang et al., 2014; Zheng et al., 2014). Both pathogenic and protective functions of NK cells in viral infections have been reported (Jost and Altfeld, 2013; Schuch et al., 2014), but it is unclear whether liver trNK cells and $\mathrm{cNK}$ cells play similar or distinct roles in anti-viral immune responses. Like cNK cells, liver trNK cells are cytotoxic and IFN- $\gamma$ producers (Sojka et al., 2014a). It is possible that liver trNK cells may spontaneously lyse virus-infected hepatocytes and promote Th1 polarization via IFN- $\gamma$, thereby contributing to viral clearance in the liver. However, trNK cells have also been found to have immune-regulatory functions through crosstalk with other immune cells. For example, salivary gland trNK cells, which highly express TRAIL, eliminate activated $\mathrm{CD} 4^{+} \mathrm{T}$ cells in a TRAIL-dependent manner and consequently delay viral clearance during chronic murine cytomegalovirus (MCMV) infection (Schuster et al., 2014). Liver trNK cells express high levels of NKG2A; a recent study found that signalling through NKG2A inhibited accumulation of IFN- $\gamma^{+} \mathrm{cNK}$ and thereby limited antiviral $\mathrm{CD} 8^{+} \mathrm{T}$ cell responses (Krueger et al., 2016), suggestive of the immune-regulatory potential of liver trNK cells. Moreover, our previous study showed that genes associated with immune tolerance and negative regulations were upregulated in liver trNK cells as compared to those in cNK cells. Therefore, liver trNK cells also have the potential to negatively regulate anti-viral immune responses.

\section{CD49A AS A COMMON MARKER FOR TRNK CELLS}

The discovery of liver trNK cells motivates the study of trNK cells in other tissues, which provides new insights into the heterogeneity of NK cell subsets. Recent findings have revealed that trNK cells in different tissues have striking phenotypic features similar to those in the liver (Erick and Brossay, 
2016).

CD49a is also known as integrin $\alpha 1$ and can associate with the integrin $\beta 1$ subunit (CD29) to form the CD49a/CD29 (VLA-1) heterodimer, which is responsible for retaining lymphocytes in tissues (Ray et al., 2004; Richter et al., 2007). By parabiosis studies, CD49a was also found to be a marker of trNK cells in other tissues. Akin to the liver, uterus, skin and adipose contain high frequency of CD49a $\mathrm{a}^{+} \mathrm{D} 5^{-} \mathrm{trNK}$ cells (Richter et al., 2007; Sojka et al., 2014a). In contrast to liver and skin trNK cells, uterus NK cells are T-bet-independent and express high levels of Eomes (Sojka et al., 2014a; Tayade et al., 2005). Interestingly, salivary gland NK cells are tissue-resident and exhibit positivity for both CD49a and DX5 (Cortez et al., 2016). Unlike trNK cells in other tissues, salivary gland NK cells are present in normal numbers in T-bet-, Eomes-, and NFIL3-deficient mice, but lack of TGF- $\beta$-signaling markedly reduced salivary gland NK cell numbers (Cortez et al., 2014; Cortez et al., 2016). In addition to $\mathrm{CD} 49 \mathrm{a}$, several other markers commonly expressed by trNK cells have been reported, including CD69 and TRAIL. CD69 can antagonize sphingosine-1 phosphate receptor 1 (S1P1) (Bankovich et al., 2010; Shiow et al., 2006), which promotes lymphocyte egress in to blood (Zajac and Harrington, 2014), and thus it could be relevant to the tissue residency of non-cNK cell subsets. Similarly, other non-recirculating lymphoid lineages, such as tissue-resident memory T (Trm) and NKT cells, also highly express CD49a and CD69 (Mackay et al., 2016). Moreover, Trm and NKT cells also require Hobit for their maintenance, like liver trNK cells (Mackay et al., 2016). Collectively, trNK cells and other tissue-resident lymphocytes exhibit shared expression patterns of surface markers and transcriptional factors that instructs tissue retention.

\section{LIVER TRNK CELLS: FROM MOUSE TO HUMAN}

In humans, liver NK cells with equal proportions of CD56 $6^{\text {bright }}$ and $\mathrm{CD}_{56} 6^{\mathrm{dim}}$ subsets can account up to $30 \%-40 \%$ of total hepatic lymphocytes (Moroso et al., 2010), in contrast to their low frequency in other tissues. Previous studies about human liver NK cells have been mainly focused on their roles in liver diseases including viral infections, fibrosis, and tumors (Araujo et al., 2014; Fasbender et al., 2016; Rehermann, 2013); however, few studies have specifically descripted the characteristics of human liver NK cells under homeostatic conditions. The discovery of liver trNK cells in mice prompted researchers to further investigate whether the human liver also contains a unique trNK cell subset. In humans, liver CD56 ${ }^{\mathrm{dim}} \mathrm{NK}$ cell subset phenotypically and functionally resembles peripheral blood CD56 ${ }^{\text {dim }} \mathrm{NK}$ cells, which represent at least $90 \%$ of all peripheral blood NK cells, and thus can be regarded as cNK cells (Hudspeth et al., 2016).
In contrast to CD56 ${ }^{\mathrm{dim}} \mathrm{cNK}$ cells, hepatic CD56 ${ }^{\text {bright }} \mathrm{NK}$ cells express trNK cell markers such as CD69 and CXCR6, and lack cNK cell markers such as CD62L and CCR7 (Burt et al., 2009; Hudspeth et al., 2016). Moreover, human hepatic CD56 ${ }^{\text {bright }} \mathrm{NK}$ cells exhibit unique transcriptional profiles compared to cNK cells. CCL3, CCL4, CXCL16, which are highly expressed in the sinusoids of the healthy liver, can selectively induce migration of hepatic CD56 $6^{\text {bright }} \mathrm{NK}$ cells (Hudspeth et al., 2016), hinting at a possible mechanism for their retention in the human liver.

Similar to murine liver trNK cells, a proportion of human hepatic CD56 $6^{\text {bright }}$ NK cells with the expression of CD49a are T-bet ${ }^{+}$Eomes $^{-}$(Marquardt et al., 2015). Interestingly, these $\mathrm{CD} 49 \mathrm{a}^{+} \mathrm{NK}$ cells display a narrow killer cell Ig-like receptor (KIR) expression pattern, suggestive of having undergone clonal-like expansion. Inconsistent with the highly frequency (about $50 \%$ ) of murine liver trNK cells, however, human hepatic $\mathrm{CD} 49 \mathrm{a}^{+} \mathrm{NK}$ cells are at a very low frequency (average $2.3 \%$ ) and even undetectable in some cases (Marquardt et al., 2015). Therefore, the precise identification of human liver trNK cells remains to be further studied.

\section{CONCLUDING REMARKS}

Recent studies have indicated that the liver contains two distinct NK cell subsets: trNK cells and cNK cells. There are substantial differences between the two subsets in terms of phenotype, functions, and developmental requirements. The discovery of liver trNK cells led to the investigation of trNK cells in other tissues, which has greatly expanded our knowledge of NK cell diversity. However, many new questions concurrently arise, and the following issues need to be addressed in future studies: (i) the origin of trNK cells in different tissues, (ii) the local environmental factors involved in the tissue residency and maintenance of trNK cells, (iii) contribution of trNK cells in the progress of different diseases such as infection and inflammatory diseases, (iv) molecular mechanisms underlying memory-like responses by liver trNK cells, and (v) precise identification of human trNK cells. Addressing the above questions has an enormous potential not only to improve our knowledge on NK cell biology but also to facilitate future clinical applications of NK cell-based immunotherapy.

Compliance and ethics The author(s) declare that they have no conflict of interest.

Acknowledgements This work was supported by the Ministry of Science \& Technology of China (2013CB944902), and the Natural Science Foundation of China (81361120388, 81571522, 31300727, 91542114, 91442112)

Araujo, P., Gonçalves, G., Latini, F., Ferreira, O., Porto, L.C., Barreto, J.A., Girao, M.J.C., and Diaz, R.S. (2014). KIR and a specific $H L A-C$ gene are associated with susceptibility and resistance to hepatitis $\mathrm{B}$ virus infection 
in a Brazilian population. Cell Mol Immunol 11, 609-612.

Bankovich, A.J., Shiow, L.R., and Cyster, J.G. (2010). CD69 suppresses sphingosine 1-phosophate receptor-1 (S1P1) function through interaction with membrane Helix 4. J Biol Chem 285, 22328-22337.

Burt, B.M., Plitas, G., Zhao, Z., Bamboat, Z.M., Nguyen, H.M., Dupont, B., and DeMatteo, R.P. (2009). The lytic potential of human liver NK cells is restricted by their limited expression of inhibitory killer Ig-like receptors. J Immunol 183, 1789-1796.

Constantinides, M.G., McDonald, B.D., Verhoef, P.A., and Bendelac, A. (2014). A committed precursor to innate lymphoid cells. Nature 508, 397-401.

Cooper, M.A., Elliott, J.M., Keyel, P.A., Yang, L., Carrero, J.A., and Yokoyama, W.M. (2009). Cytokine-induced memory-like natural killer cells. Proc Natl Acad Sci USA 106, 1915-1919.

Cortez, V.S., Cervantes-Barragan, L., Robinette, M.L., Bando, J.K., Wang, Y., Geiger, T.L., Gilfillan, S., Fuchs, A., Vivier, E., Sun, J.C., Cella, M., and Colonna, M. (2016). Transforming growth factor- $\beta$ signaling guides the differentiation of innate lymphoid cells in salivary glands. Immunity 44, 1127-1139.

Cortez, V.S., Fuchs, A., Cella, M., Gilfillan, S., and Colonna, M. (2014). Cutting edge: salivary gland NK cells develop independently of Nfil3 in steady-state. J Immunol 192, 4487-4491.

Crosbie, O.M., Reynolds, M., McEntee, G., Traynor, O., Hegarty, J.E., and O'Farrelly, C. (1999). In vitro evidence for the presence of hematopoietic stem cells in the adult human liver. Hepatology 29, 1193-1198.

Crotta, S., Gkioka, A., Male, V., Duarte, J.H., Davidson, S., Nisoli, I., Brady, H.J.M., and Wack, A. (2014). The transcription factor E4BP4 is not required for extramedullary pathways of NK cell development. J Immunol 192, 2677-2688.

Dahlberg, C.I.M., Sarhan, D., Chrobok, M., Duru, A.D., and Alici, E. (2015). Natural killer cell-based therapies targeting cancer: possible strategies to gain and sustain anti-tumor activity. Front Immunol 6, 605.

Daussy, C., Faure, F., Mayol, K., Viel, S., Gasteiger, G., Charrier, E., Bienvenu, J., Henry, T., Debien, E., Hasan, U.A., Marvel, J., Yoh, K., Takahashi, S., Prinz, I., de Bernard, S., Buffat, L., and Walzer, T. (2014). T-bet and Eomes instruct the development of two distinct natural killer cell lineages in the liver and in the bone marrow. J Exp Med 211, 563-577.

Eissens, D.N., Michelo, C.M., Preijers, F.W.M.B., van Cranenbroek, B., van Houwelingen, K., van der Meer, A., and Joosten, I. (2014). Selective expansion of human natural killer cells leads to enhanced alloreactivity. Cell Mol Immunol 11, 160-168.

Erick, T.K., and Brossay, L. (2016). Phenotype and functions of conventional and non-conventional NK cells. Curr Opin Immunol 38, 67-74.

Fahey, S., Dempsey, E., and Long, A. (2014). The role of chemokines in acute and chronic hepatitis $\mathrm{C}$ infection. Cell Mol Immunol 11, 25-40.

Fasbender, F., Widera, A., Hengstler, J.G., and Watzl, C. (2016). Natural killer cells and liver fibrosis. Front Immunol 7, 19.

Foley, B., Cooley, S., Verneris, M.R., Curtsinger, J., Luo, X., Waller, E.K., Anasetti, C., Weisdorf, D., and Miller, J.S. (2012). Human cytomegalovirus (CMV)-induced memory-like $\mathrm{NKG}_{2} \mathrm{C}^{+} \mathrm{NK}$ cells are transplantable and expand in vivo in response to recipient $\mathrm{CMV}$ antigen. J Immunol 189, 5082-5088.

Gao, B., Jeong, W.I., and Tian, Z. (2008). Liver: an organ with predominant innate immunity. Hepatology 47, 729-736.

Gasteiger, G., Fan, X., Dikiy, S., Lee, S.Y., and Rudensky, A.Y. (2015). Tissue residency of innate lymphoid cells in lymphoid and nonlymphoid organs. Science 350, 981-985.

Geiger, T.L., Abt, M.C., Gasteiger, G., Firth, M.A., O’Connor, M.H., Geary, C.D., O'Sullivan, T.E., van den Brink, M.R., Pamer, E.G., Hanash, A.M., and Sun, J.C. (2014). Nfil3 is crucial for development of innate lymphoid cells and host protection against intestinal pathogens. J Exp Med 211, $1723-1731$.

Gillard, G.O., Bivas-Benita, M., Hovav, A.H., Grandpre, L.E., Panas, M.W., Seaman, M.S., Haynes, B.F., and Letvin, N.L. (2011). Thy $1^{+}$Nk cells from vaccinia virus-primed mice confer protection against vaccinia virus challenge in the absence of adaptive lymphocytes. PLoS Pathog 7, e1002141.

Gordon, S.M., Chaix, J., Rupp, L.J., Wu, J., Madera, S., Sun, J.C., Lindsten, T., and Reiner, S.L. (2012). The transcription factors T-bet and eomes control key checkpoints of natural killer cell maturation. Immunity 36 , 55-67.

Hudspeth, K., Donadon, M., Cimino, M., Pontarini, E., Tentorio, P., Preti, M., Hong, M., Bertoletti, A., Bicciato, S., Invernizzi, P., Lugli, E., Torzilli, G., Gershwin, M.E., and Mavilio, D. (2016). Human liver-resident $\mathrm{CD} 56^{\text {bright }} / \mathrm{CD} 16^{\text {neg }} \mathrm{NK}$ cells are retained within hepatic sinusoids via the engagement of CCR5 and CXCR6 pathways. J Autoimmun 66, 40-50.

Jenne, C.N., and Kubes, P. (2013). Immune surveillance by the liver. Nat Immunol 14, 996-1006.

Jost, S., and Altfeld, M. (2013). Control of human viral infections by natural killer cells. Annu Rev Immunol 31, 163-194.

Keppel, M.P., Yang, L., and Cooper, M.A. (2013). Murine NK cell intrinsic cytokine-induced memory-like responses are maintained following homeostatic proliferation. J Immunol 190, 4754-4762.

Kim, S., Iizuka, K., Kang, H.S.P., Dokun, A., French, A.R., Greco, S., and Yokoyama, W.M. (2002). In vivo developmental stages in murine natural killer cell maturation. Nat Immunol 3, 523-528.

Klose, C.S.N., Flach, M., Möhle, L., Rogell, L., Hoyler, T., Ebert, K., Fabiunke, C., Pfeifer, D., Sexl, V., Fonseca-Pereira, D., Domingues, R.G., Veiga-Fernandes, H., Arnold, S.J., Busslinger, M., Dunay, I.R., Tanriver, Y., and Diefenbach, A. (2014). Differentiation of type 1 ILCs from a common progenitor to all helper-like innate lymphoid cell lineages. Cell 157, 340-356.

Kotton, D.N., Fabian, A.J., and Mulligan, R.C. (2005). A novel stem-cell population in adult liver with potent hematopoietic-reconstitution activity. Blood 106, 1574-1580.

Krueger, P.D., Narayanan, S., Surette, F.A., Brown, M.G., Sung, S.S.J., and Hahn, Y.S. (2016). Murine liver-resident group 1 innate lymphoid cells regulate optimal priming of anti-viral $\mathrm{CD}^{+} \mathrm{T}$ cells. J Leukocyte Biol in press, doi: 10.1189/jlb.3A0516-225R.

Ma, Z., Zhang, E., Yang, D., and Lu, M. (2015). Contribution of Toll-like receptors to the control of hepatitis $B$ virus infection by initiating antiviral innate responses and promoting specific adaptive immune responses. Cell Mol Immunol 12, 273-282.

Mackay, L.K., Minnich, M., Kragten, N.A.M., Liao, Y., Nota, B., Seillet, C., Zaid, A., Man, K., Preston, S., Freestone, D., Braun, A., Wynne-Jones, E., Behr, F.M., Stark, R., Pellicci, D.G., Godfrey, D.I., Belz, G.T., Pellegrini, M., Gebhardt, T., Busslinger, M., Shi, W., Carbone, F.R., van Lier, R.A.W., Kallies, A., and van Gisbergen, K.P.J.M. (2016). Hobit and Blimp1 instruct a universal transcriptional program of tissue residency in lymphocytes. Science 352, 459-463.

Marquardt, N., Béziat, V., Nyström, S., Hengst, J., Ivarsson, M.A., Kekäläinen, E., Johansson, H., Mjösberg, J., Westgren, M., Lankisch, T.O., Wedemeyer, H., Ellis, E.C., Ljunggren, H.G., Michaëlsson, J., and Björkström, N.K. (2015). Cutting edge: identification and characterization of human intrahepatic CD49a ${ }^{+}$NK cells. JI 194, 2467-2471.

Moroso, V., Metselaar, H.J., Mancham, S., Tilanus, H.W., Eissens, D., van der Meer, A., van der Laan, L.J.W., Kuipers, E.J., Joosten, I., and Kwekkeboom, J. (2010). Liver grafts contain a unique subset of natural killer cells that are transferred into the recipient after liver transplantation. Liver Transpl 16, 895-908.

O’Leary, J.G., Goodarzi, M., Drayton, D.L., and von Andrian, U.H. (2006). $\mathrm{T}$ cell- and $\mathrm{B}$ cell-independent adaptive immunity mediated by natural killer cells. Nat Immunol 7, 507-516.

O’Sullivan, T.E., Sun, J.C., and Lanier, L.L. (2015). Natural killer cell memory. Immunity 43, 634-645.

Orkin, S.H., and Zon, L.I. (2008). Hematopoiesis: an evolving paradigm for stem cell biology. Cell 132, 631-644.

Paust, S., Gill, H.S., Wang, B.Z., Flynn, M.P., Moseman, E.A., Senman, B., Szczepanik, M., Telenti, A., Askenase, P.W., Compans, R.W., and von Andrian, U.H. (2010). Critical role for the chemokine receptor CXCR6 
in NK cell-mediated antigen-specific memory of haptens and viruses. Nat Immunol 11, 1127-1135.

Peng, H., Jiang, X., Chen, Y., Sojka, D.K., Wei, H., Gao, X., Sun, R., Yokoyama, W.M., and Tian, Z. (2013). Liver-resident NK cells confer adaptive immunity in skin-contact inflammation. J Clin Invest 123, $1444-1456$.

Peng, H., and Tian, Z. (2015). Re-examining the origin and function of liverresident NK cells. Trends Immunol 36, 293-299.

Racanelli, V., and Rehermann, B. (2006). The liver as an immunological organ. Hepatology 43, S54-S62.

Rajagopalan, S. (2014). HLA-G-mediated NK cell senescence promotes vascular remodeling: implications for reproduction. Cell Mol Immunol 11, 460-466.

Ray, S.J., Franki, S.N., Pierce, R.H., Dimitrova, S., Koteliansky, V., Sprague, A.G., Doherty, P.C., de Fougerolles, A.R., and Topham, D.J. (2004). The collagen binding $\alpha 1 \beta 1$ integrin VLA-1 regulates CD8 T cell-mediated immune protection against heterologous influenza infection. Immunity $20,167-179$

Rehermann, B. (2013). Pathogenesis of chronic viral hepatitis: differential roles of T cells and NK cells. Nat Med 19, 859-868.

Richter, M., Ray, S.J., Chapman, T.J., Austin, S.J., Rebhahn, J., Mosmann, T.R., Gardner, H., Kotelianski, V., deFougerolles, A.R., and Topham, D.J. (2007). Collagen distribution and expression of collagen-binding $\alpha 1 \beta 1$ (VLA-1) and $\alpha 2 \beta 1$ (VLA-2) integrins on CD4 and CD8 T cells during influenza infection. J Immunol 178, 4506-4516.

Schuch, A., Hoh, A., and Thimme, R. (2014). The role of natural killer cells and $\mathrm{CD}^{+} \mathrm{T}$ cells in hepatitis B virus infection. Front Immunol 5, 258.

Schuster, I.S., Wikstrom, M.E., Brizard, G., Coudert, J.D., Estcourt, M.J., Manzur, M., O'Reilly, L.A., Smyth, M.J., Trapani, J.A., Hill, G.R., Andoniou, C.E., and Degli-Esposti, M.A. (2014). TRAIL ${ }^{+}$NK cells control $\mathrm{CD}^{+} \mathrm{T}$ cell responses during chronic viral infection to limit autoimmunity. Immunity 41, 646-656.

Seillet, C., Huntington, N.D., Gangatirkar, P., Axelsson, E., Minnich, M., Brady, H.J.M., Busslinger, M., Smyth, M.J., Belz, G.T., and Carotta, S. (2014a). Differential requirement for Nfil3 during NK cell development. J Immunol 192, 2667-2676.

Seillet, C., Rankin, L.C., Groom, J.R., Mielke, L.A., Tellier, J., Chopin, M., Huntington, N.D., Belz, G.T., and Carotta, S. (2014b). Nfil3 is required for the development of all innate lymphoid cell subsets. J Exp Med 211, $1733-1740$.

Shi, F.D., Ljunggren, H.G., La Cava, A., and Van Kaer, L. (2011). Organspecific features of natural killer cells. Nat Rev Immunol 11, 658-671.

Shiow, L.R., Rosen, D.B., Brdicková, N., Xu, Y., An, J., Lanier, L.L., Cyster, J.G., and Matloubian, M. (2006). CD69 acts downstream of interferon$\alpha / \beta$ to inhibit S1P1 and lymphocyte egress from lymphoid organs. Nature $440,540-544$

Sojka, D.K., Plougastel-Douglas, B., Yang, L., Pak-Wittel, M.A., Artyomov, M.N., Ivanova, Y., Zhong, C., Chase, J.M., Rothman, P.B., Yu, J., Riley, J.K., Zhu, J., Tian, Z., and Yokoyama, W.M. (2014a). Tissue-resident natural killer (NK) cells are cell lineages distinct from thymic and conventional splenic NK cells. eLife 3, e01659.
Sojka, D.K., Tian, Z., and Yokoyama, W.M. (2014b). Tissue-resident natural killer cells and their potential diversity. Semin Immunol 26, 127-131.

Spits, H., and Di Santo, J.P. (2011). The expanding family of innate lymphoid cells: regulators and effectors of immunity and tissue remodeling. Nat Immunol 12, 21-27.

Sun, C., Sun, H., Zhang, C., and Tian, Z. (2015). NK cell receptor imbalance and $\mathrm{NK}$ cell dysfunction in $\mathrm{HBV}$ infection and hepatocellular carcinoma. Cell Mol Immunol 12, 292-302.

Sun, J.C., Beilke, J.N., and Lanier, L.L. (2009). Adaptive immune features of natural killer cells. Nature 457, 557-561.

Takeda, K., Cretney, E., Hayakawa, Y., Ota, T., Akiba, H., Ogasawara, K., Yagita, H., Kinoshita, K., Okumura, K., and Smyth, M.J. (2005). TRAIL identifies immature natural killer cells in newborn mice and adult mouse liver. Blood 105, 2082-2089.

Tang, L., Peng, H., Zhou, J., Chen, Y., Wei, H., Sun, R., Yokoyama, W.M., and Tian, Z. (2016). Differential phenotypic and functional properties of liver-resident NK cells and mucosal ILC1s. J Autoimmun 67, 29-35.

Taniguchi, H., Toyoshima, T., Fukao, K., and Nakauchi, H. (1996). Presence of hematopoietic stem cells in the adult liver. Nat Med 2, 198-203.

Tayade, C., Fang, Y., Black, G.P., V A, P., Erlebacher, A., and Croy, B.A. (2005). Differential transcription of Eomes and T-bet during maturation of mouse uterine natural killer cells. J Leukocyte Biol 78, 1347-1355.

Wang, X.Q., Lo, C.M., Chen, L., Cheung, C.K.Y., Yang, Z.F., Chen, Y.X., Ng, M.N., Yu, W.C., Ming, X., Zhang, W., Ho, D.W.Y., Chan, S.C., and Fan, S.T. (2012). Hematopoietic chimerism in liver transplantation patients and hematopoietic stem/progenitor cells in adult human liver. Hepatology 56, 1557-1566.

Xu, R., Huang, H., Zhang, Z., and Wang, F.S. (2014). The role of neutrophils in the development of liver diseases. Cell Mol Immunol 11, 224-231.

Yang, D., Liu, L., Zhu, D., Peng, H., Su, L., Fu, Y.X., and Zhang, L. (2014). A mouse model for HBV immunotolerance and immunotherapy. Cell Mol Immunol 11, 71-78.

Yang, Q., Li, F., Harly, C., Xing, S., Ye, L., Xia, X., Wang, H., Wang, X., Yu, S., Zhou, X., Cam, M., Xue, H.H., and Bhandoola, A. (2015). TCF-1 upregulation identifies early innate lymphoid progenitors in the bone marrow. Nat Immunol 16, 1044-1050.

Yokoyama, W.M., Sojka, D.K., Peng, H., and Tian, Z. (2013). Tissue-resident natural killer cells. Cold Spring Harb Symp Quant Biol 78, 149-156.

Yu, X., Wang, Y., Deng, M., Li, Y., Ruhn, K.A., Zhang, C.C., and Hooper, L.V. (2014). The basic leucine zipper transcription factor NFIL3 directs the development of a common innate lymphoid cell precursor. eLife 3, e04406.

Zajac, A.J., and Harrington, L.E. (2014). Tissue-resident T cells lose their S1P1 exit visas. Cell Mol Immunol 11, 221-223.

Zheng, J., Liang, H., Xu, C., Xu, Q., Zhang, T., Shen, T., and Lu, F. (2014). An unbalanced PD-L1/CD86 ratio in $\mathrm{CD} 14^{++} \mathrm{CD} 16^{+}$monocytes is correlated with $\mathrm{HCV}$ viremia during chronic $\mathrm{HCV}$ infection. Cell Mol Immunol 11, 294-304.

Zook, E.C., and Kee, B.L. (2016). Development of innate lymphoid cells. Nat Immunol 17, 775-782.

Open Access This article is distributed under the terms of the Creative Commons Attribution License which permits any use, distribution, and reproduction in any medium, provided the original author(s) and source are credited. 